\title{
2-FENILBENZOTRIAZÓIS (PBTA): UMA NOVA CLASSE DE CONTAMINANTES AMBIENTAIS
}

\section{Fábio Kummrow*}

Departamento de Análises Clínicas e Toxicológicas, Universidade Federal de Alfenas, Rua Gabriel Monteiro da Silva, 714, 37130-000 Alfenas - MG, Brasil

Gisela de Aragão Umbuzeiro

Divisão de Toxicologia, Genotoxicidade e Microbiologia Ambiental, Companhia de Tecnologia de Saneamento Ambiental, Av. Prof. Frederico Hermann Jr., 345, 05459-900 São Paulo - SP, Brasil

\begin{abstract}
2-PHENYLBENZOTRIAZOLES (PBTAs): A NEW CLASS OF ENVIRONMENTAL CONTAMINANTS. This work is a literature review of PBTAs, the phenylbenzotriazoles generated from the reduction and chlorination of azo dyes. The PBTAs and the nonchlorinated PBTAs were isolated for the first time from river blue rayon organic extracts that showed high mutagenic activity in the Salmonella/microsome genotoxicity assay. To date, 8 PBTAs have been identified and beside their mutagenic activity in bacteria they cause genotoxic effects in fish and mammalian cell cultures. Due to the large number of textile dyeing facilities in Brazil, studies to determine them in the aquatic environment seem to be relevant.
\end{abstract}

Keywords: 2-phenylbenzotriazole-type mutagens; PBTAs; genotoxic environmental contaminants.

\section{INTRODUÇÃO}

Freqüentemente, compostos químicos na forma de misturas complexas são lançados no ambiente e muitos são tóxicos e/ou genotóxicos. Além dos próprios compostos originalmente lançados, uma grande variedade de produtos desconhecidos pode ser gerada no próprio ambiente, por processos bióticos e abióticos ${ }^{1}$. Devido a esses fatores, análises químicas realizadas para a determinação apenas dos compostos químicos conhecidos, considerados prioritários, e para os quais se têm metodologias analíticas padronizadas, fornecem informações limitadas sobre o potencial tóxico dessas misturas ${ }^{1,2}$.

Uma ferramenta desenvolvida para auxiliar a identificação de compostos orgânicos tóxicos e/ou genotóxicos desconhecidos, presentes em misturas complexas ambientais, é o conjunto de procedimentos conhecido como Análises químicas direcionadas pelo efeito biológico (ADEB), "Effect-directed analysis". Essa estratégia analítica, que combina técnicas de extração e/ou "clean up", fracionamento de extratos, bioensaios e análises químicas ${ }^{2}$, tem sido utilizada com sucesso na identificação de novas classes de contaminantes ambientais ${ }^{1}$. Dentre os contaminantes ou classe de contaminantes identificados com auxílio dessa estratégia estão alguns nitro-HPA como o 3-nitrobenzantrona (3-NBA) ${ }^{3}$, os produtos de desinfecção das águas gerados durante o processo de cloração, como o 3-cloro-4(diclorometil)-5-5-hidróxi-2(5H)-furanona (MX) ${ }^{4}$ e, recentemente, os 2-fenilbenzotriazóis (PBTA) ${ }^{5}$.

Os 2-fenilbenzotriazóis (PBTA) são compostos genotóxicos que foram identificados pela primeira vez com auxílio do blue rayon como técnica seletiva de extração/concentração, associado ao teste Salmonella/microssoma nas águas do rio Nishitakase em Kyoto, Japão ${ }^{5}$. Esses compostos são formados a partir de corantes azóicos, utilizados principalmente em unidades de tingimento de produtos têxteis, e podem ser produzidos durante o próprio processo industrial, ou em estações de tratamento de efluentes ou esgotos. As etapas do processo industrial de tingimento, bem como do tratamento

\footnotetext{
*e-mail: fabiok@unifal-mg.edu.br
}

de efluentes resultantes, incluem redução com hidrossulfito de sódio para descoloração dos corantes remanescentes, levando à formação dos PBTA não-clorados. Estes, no processo de cloração realizado para desinfecção dos efluentes, são convertidos nos $\mathrm{PBTA}^{6-8}$ listados na Tabela 1. Até hoje foram descritos por diferentes autores oito PBTA, os quais estão apresentados na Figura 1.

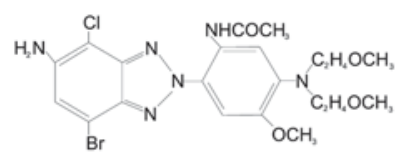

PBTA-1<smiles>COc1cc(N2N=C3C(Br)=CC(N)=C(Cl)C3N2)c(NC=O)cc1OC=O</smiles>

PBTA-3<smiles>COC(=O)OCN(C=O)c1cc(OC(C)=O)c(N2NC3C(Br)=CC(N)=C(Cl)C3N2)cc1OC</smiles><smiles>CCN(CC)c1cc(N2N=C3C(Br)=CC(N)=C(Cl)C3N2)c(N=O)cc1OC</smiles>

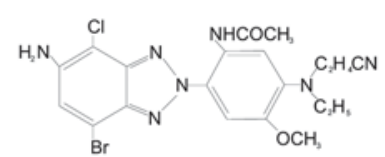

PBTA-2

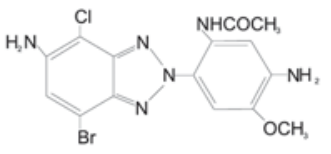

PBTA-4

PBTA-6

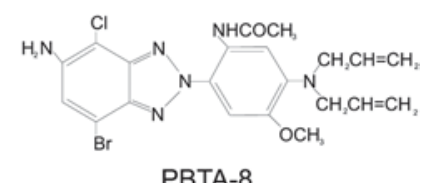

PBTA-8

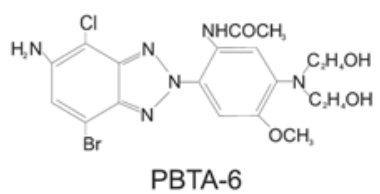

Figura 1. Estruturas químicas dos oito PBTA já identificados

\section{PRESENÇA DOS PBTA NO MEIO AMBIENTE}

Os diferentes bioensaios utilizados para avaliação da mutagenicidade de misturas complexas têm demonstrado que as amostras ambientais, como por exemplo as águas superficiais, con- 
Tabela 1. Nome dos oito PBTA já sintetizados, seus precursores (corantes azóicos) e suas formas não-cloradas (PBTA não-clorado)

\begin{tabular}{|c|c|c|c|}
\hline PBTA & Corante azóico & PBTA não-clorado & Ref. \\
\hline $\begin{array}{l}\text { PBTA-1 } \\
\text { 2-[2-(acetilamino)-4-[bis(2- } \\
\text { metoxietil)-amino]-5-metoxifenil]- } \\
\text { 5-amino-7-bromo-4-cloro-2 } \mathrm{H} \text { - } \\
\text { benzotriazol }\end{array}$ & $\begin{array}{l}\text { 2-[(2-bromo-4,6-dinitrofenil)azo]- } \\
\text { 4-metoxi-5-[bis(2 } \\
\text {-metoxietil)amino]acetoanilida } \\
\text { (Disperse Blue 301) }\end{array}$ & $\begin{array}{l}\text { 2-[2-(acetilamino)-4-[bis }(2- \\
\text { metoxietil)-amino]-5- } \\
\text { metoxifenil]-6-amino-4- } \\
\text { bromo- } 2 \mathrm{H} \text {-benzotriazol }\end{array}$ & 25 \\
\hline $\begin{array}{l}\text { PBTA-2 } \\
\text { 2-[2-(acetilamino)-4-[N-(2- } \\
\text { cianoetil)etilamino]-5- } \\
\text { metoxifenil]- 5-amino-7-bromo-4- } \\
\text { cloro-2 } \mathrm{H} \text {-benzotriazol }\end{array}$ & $\begin{array}{l}\text { 2-[(2-bromo-4,6-dinitrofenil)azo]- } \\
\text { 5-[N-(2-cianoetil)etilamino]-4- } \\
\text { metoxiacetanilida }\end{array}$ & $\begin{array}{l}\text { 2-[2-(acetilamino)-4-[N-(2- } \\
\text { cianoetil)etilamino]-5- } \\
\text { metoxifenil]-6-amino-4- } \\
\text { bromo- } 2 \mathrm{H} \text {-benzotriazol }\end{array}$ & 15 \\
\hline $\begin{array}{l}\text { PBTA-3 } \\
\text { 2-[2-(acetilamino)-4-[(2- } \\
\text { hidroxietil)-amino]-5-metoxifenil]- } \\
\text { 5-amino-7-bromo-4-cloro- } \mathrm{H} \text { - } \\
\text { benzotriazol }\end{array}$ & $\begin{array}{l}\text { 2-[(2-bromo-4,6-dinitrofenil)azo]- } \\
\text { 4-metoxi-5-[(2-hidrixietil)amino] } \\
\text { acetanilida }\end{array}$ & $\begin{array}{l}\text { 2-[(2-(acetilamino)-4-[(2- } \\
\text { hidroxietil)-amino]-5- } \\
\text { metoxifenil]-6-amino-4- } \\
\text { bromo- } 2 \mathrm{H} \text {-benzotriazol }\end{array}$ & 16 \\
\hline $\begin{array}{l}\text { PBTA-4 } \\
\text { 2-[2-(acetilamino)-4-amino-5 } \\
\text { metoxifenil]-5-amino-7-bromo- } \\
\text { 4-cloro-2H-benzotriazol }\end{array}$ & $\begin{array}{l}\text { 5-amino-2-[(2-bromo-4,6- } \\
\text { dinitrofenil)azo]-5-amino- } \\
\text { 4-metoxiacetanilida }\end{array}$ & $\begin{array}{l}\text { 2-(2-acetilamino-4-amino- } \\
\text { 5-metoxifenil)-6-amino-4- } \\
\text { bromo- } 2 \mathrm{H} \text {-benzotriazol }\end{array}$ & 7 \\
\hline $\begin{array}{l}\text { PBTA-5 } \\
\text { 2-[4-[bis(2-acetoxietil)amino]-2- } \\
\text { (acetilamino)-5-metoxifenil]-5- } \\
\text { amino-7-bromo-4-cloro- } 2 \mathrm{H} \text { - } \\
\text { benzotriazol }\end{array}$ & $\begin{array}{l}\mathrm{N} \text {-[5[bis[2-(acetiloxi)etil]amino]-2- } \\
\text { [( 2-bromo-4,6-dinitrofenil)azo]-4- } \\
\text { metoxifenil]acetamida } \\
\text { (Disperse Blue 79:1) }\end{array}$ & $\begin{array}{l}\text { 2-[2-(acetilamino)-4- } \\
\text { [bis(2-acetiloxietil)amino]- } \\
\text { 5-metoxifenil]-6-amino- } \\
\text { 4-bromo- } 2 H \text {-benzotriazol }\end{array}$ & 17 \\
\hline $\begin{array}{l}\text { PBTA-6 } \\
\text { 2-[2-(acetilamino)-4-[bis(2-hidroxietil) } \\
\text { amino]-5-metoxifenil]-5-amino-7-bromo- } \\
\text { 4-cloro-2H-benzotriazol }\end{array}$ & $\begin{array}{l}\mathrm{N} \text {-[5[bis[2-(acetiloxi)etil]amino]-2- } \\
{[(2 \text {-bromo-4,6-dinitrofenil)azo]-4- }} \\
\text { metoxifenil]acetamida } \\
\text { (Disperse Blue } 79: 1)\end{array}$ & $\begin{array}{l}\text { 2-[2-(acetilamino)-4-[bis } \\
\text { (2-acetiloxietil)amino]-5- } \\
\text { metoxifenil]-6-amino-4- } \\
\text { bromo- } 2 H \text {-benzotriazol }\end{array}$ & 17 \\
\hline $\begin{array}{l}\text { PBTA-7 } \\
\text { 2-[2-(acetilamino)-4-(dietilamino)-5- } \\
\text { metoxifenil]-5-amino-7-bromo-4-cloro- } \\
2 \mathrm{H} \text {-benzotriazol }\end{array}$ & $\begin{array}{l}\text { 2-[(2-bromo-4,6-dinitrofenil)azo]-5- } \\
\text { (dietilamino)-4-metoxi-acetanilida } \\
\text { (Disperse Blue 291) }\end{array}$ & $\begin{array}{l}\text { 2-[(2-(acetilamino)-4- } \\
\text { (dietilamino)-5-metoxifenil]- } \\
\text { 6-amino-4-bromo- } \\
\text { 2H-benzotriazol }\end{array}$ & 18 \\
\hline $\begin{array}{l}\text { PBTA-8 } \\
\text { 2-[2-(acetilamino)-4-(dialilamino)-5- } \\
\text { metoxifenil]-5-amino-7-bromo-4-cloro- } \\
\text { 2H-benzotriazol }\end{array}$ & $\begin{array}{l}\text { 2-[(2-bromo-4,6-dinitrofenil)azo]-5- } \\
\text { (dialilamino)-4-metoxi-acetanilida } \\
\text { (Disperse Blue } 373 \text { ) }\end{array}$ & $\begin{array}{l}\text { 2-[(2-(acetilamino)-4- } \\
\text { (dialilamino)-5-metoxifenil]- } \\
\text { 6-amino-4-bromo- } 2 \mathrm{H} \text { - } \\
\text { benzotriazol }\end{array}$ & 18 \\
\hline
\end{tabular}

têm muitos toxicantes ainda não identificados e não regulados que podem ser carcinogênicos e, assim, representar um risco à saúde humana de magnitude desconhecida9. A utilização de técnicas seletivas de extração/concentração de amostras, como o blue rayon, associadas a diferentes linhagens de Salmonella typhymurium do teste de Salmonella/microssoma podem sugerir as principais classes de contaminantes genotóxicos presentes no ambiente avaliado ${ }^{10-12}$.

Nukaya et al. ${ }^{13}$ utilizando a técnica de blue cotton e de blue rayon in situ ${ }^{14}$ e a linhagem de Salmonella typhimurium YG1024 verificaram importante atividade mutagênica nos extratos obtidos das águas do rio Nishitakase em Kyoto (Japão), especialmente em pontos de amostragem localizados a jusante de estações de tratamento de efluentes domésticos e industriais. Esses extratos foram fracionados por cromatografia líquida de alta eficiência (CLAE) com colunas ODS. Cinco compostos foram isolados, representando respectivamente $21,17,11,12$ e $6 \%$ da atividade mutagênica detectada no extrato total. A partir de um extrato de água obtido de $27 \mathrm{~kg}$ de blue cotton, foram isolados $1,1 \mathrm{mg}$ do composto responsável por $21 \%$ da atividade mutagênica, através de uma coluna cromatográfica Sephadex LH-20 e CLAE com coluna semi-preparativa ODS. Ainda em 1997, Nukaya et al. ${ }^{5}$ determinaram a estrutura química com base nos espectros obtidos por UV, de massas e ${ }^{1} \mathrm{H}-\mathrm{NMR}$, além de cristalografia por raio-X como sendo o 2-[2-(acetilamino)-4-[bis(2metoxietil)amino]-5-metoxifenil]-5-amino-7-bromo-4-cloro-2 $\mathrm{H}$ benzotriazol (PBTA-1). Como este composto não apresenta uso industrial conhecido, os autores sugeriram que poderia ser formado a partir de corantes presentes nos efluentes industriais, tratados nas estações de tratamento de esgotos e efluentes localizadas às margens desse rio 5 .

Oguri et al. ${ }^{15}$ identificaram outro composto, isolado dos extratos obtidos por Nukaya et al. ${ }^{13}$, que representava $17 \%$ da atividade mutagênica total observada inicialmente. Esse foi identificado e teve a estrutura determinada com o auxílio das mesmas técnicas utilizadas na identificação do PBTA-1, como sendo o 2-[2-(acetilamino)4-[ $\mathrm{N}$-(2-cianoetil)etilamino]-5-metoxifenil]-5-amino-7-bromo-4cloro- $2 \mathrm{H}$-benzotriazol, denominado PBTA-2.

No ano seguinte, Ohe et al. ${ }^{6}$ investigaram a presença dos PBTA 1 e 2 nas águas dos rios Katsura, Nishitakase, Kamo e Yodo. Amostras de $40 \mathrm{~L}$ de água desses rios foram extraídas/concentradas por blue rayon em colunas. Os extratos foram fracionados por CLAE utilizando coluna semi-preparativa TKS-GEL ODS-120A e, posteriormente, purificados em uma coluna de fase reversa CAPCELL PAK $\mathrm{C}_{18}$. As frações purificadas foram analisadas por CLAE em uma coluna analítica YMC-Pack ODS-A e detector de arranjo de 
diodos. Os PBTA 1 e 2 foram encontrados nas amostras dos rios Katsura e Nishitakase. No rio Yodo, somente o PBTA-2 foi encontrado. No rio Kamo, nenhum dos compostos foi detectado. A recuperação dos PBTA 1 e 2 foi avaliada através da adição de quantidades iguais desses compostos ( $5 \mathrm{ng} / \mathrm{L}$ de cada) às amostras fortificadas, e as recuperações obtidas foram 52 e $56 \%$, respectivamente. Os limites de detecção para esses dois compostos foram de $0,01 \mathrm{ng} / \mathrm{L}$.

Um novo composto da classe dos PBTA, o 2-[2-(acetilamino)-4[(2-hidroxietil)-amino]-5-metoxifenil]-5-amino-7-bromo-4-cloro-2 $\mathrm{H}$ benzotriazol (PBTA-3), foi identificado por Shiozawa et al. ${ }^{16}$ entre os compostos mutagênicos presentes nos extratos das águas do rio Nikko em Aichi (Japão), em pontos de coleta situados a jusante de estações de tratamento de efluentes. Neste mesmo trabalho, a presença do PBTA-3 foi observada em outros três rios, situados em áreas onde estão localizadas indústrias têxteis. As concentrações de PBTA-3 presentes nas águas dos rios Nikko, Asuwa, Katsura e Nishitakase foram $140,38,35$ e $22 \mathrm{ng} / \mathrm{g}$ de blue rayon, respectivamente.

Ainda como continuação do trabalho de Nukaya et al. ${ }^{13}$, foi identificado o composto responsável por $12 \%$ da atividade mutagênica verificada no extrato total como sendo o 2-[2-(acetilamino)-4-amino5-metoxifenil]-5-amino-7-bromo-4-cloro-2 $\mathrm{H}$-benzotriazol (PBTA$4)^{7}$. A presença desse PBTA foi verificada também em outros dois rios (Nikko e Uji). As concentrações observadas nos rios Nishitakase, Nikko e Uji, foram 32, 21 e $33 \mathrm{ng} / \mathrm{g}$ de blue rayon respectivamente.

Watanabe et al. ${ }^{17}$ sintetizaram dois novos compostos dessa classe, o 2-[4-[bis(2-acetoxietil)amino]-2-(acetilamino)-5-metoxifenil]5-amino-7-bromo-4-cloro-2 $\mathrm{H}$-benzotriazol (PBTA-5), a partir do azo corante C.I. Disperse Blue 79:1, e o 2-[2-(acetilamino)-4-[bis(2hidroxietil)amino]-5-metoxifenil]-5-amino-7-bromo-4-cloro- $2 \mathrm{H}$ benzotriazol (PBTA-6), obtido por meio da hidrólise do PBTA-5 em meio alcalino. Nesse mesmo estudo, águas de cinco rios foram analisadas para determinação desses dois novos PBTA; porém, apenas o PBTA-6 foi encontrado, em concentrações de 112, 80, 21, 3 e $134 \mathrm{ng} / \mathrm{g}$ de blue rayon nos rios Asuwa, Tobei, Nishitakase, Katsura e Uji respectivamente.

Um ano mais tarde, Watanabe et al. ${ }^{18}$ detectaram e quantificaram o 2-[2-(acetilamino)-4-(dietilamino)-5-metoxifenil]-5-amino-7bromo-4-cloro-2 $H$-benzotriazol (PBTA-7) e 2-[2-(acetilamino)-4(dialilamino)-5-metoxifenil]-5-amino-7-bromo-4-cloro-2 $\mathrm{H}$ benzotriazol (PBTA-8) em diversos rios do Japão. O PBTA-7 foi encontrado nos extratos obtidos nos rios Kitsune, Mawatari, Asuwa, Katsura e Uji e o PBTA-8 nos rios Kitsune, Asuwa, Katsura e Uji. No rio Nishitakase ambos PBTA estudados não foram encontrados, embora outros compostos dessa classe tenham sido encontrados nesse rio, conforme anteriormente citado.

Os PBTA 3, 4 e 6 foram encontrados nas águas dos rios Mawatari, Asuwa e Kitsune localizados em Fukui, no Japão, por Watanabe et al. ${ }^{19}$, utilizando blue rayon in situ e CLAE. Esses PBTA foram encontrados em $96 \%$ dos 24 extratos analisados e as quantidades encontradas para o PBTA-3 variaram entre $<0,08-58,7 \mathrm{ng} / \mathrm{g}$ de blue rayon, para o PBTA-4 entre $<0,1-15,0 \mathrm{ng} / \mathrm{g}$ de blue rayon e para o PBTA-6 entre $<0,07-467,9 \mathrm{ng} / \mathrm{g}$ de blue rayon.

Com o objetivo de verificar os níveis e o comportamento dos PBTA nos efluentes lançados no rio Uji, Morisawa et. al. ${ }^{20}$ desenvolveram um método para a determinação simultânea de seis PBTA (PBTA 1, 2, $3,4,5$ e 6) e dois PBTA não-clorados (PBTA não-clorado 1 e 2), baseado na técnica de blue rayon em colunas e determinação por CLAE, utilizando coluna de fase reversa e detector eletroquímico. Os PBTA 2, 3,4 e 6 foram detectados na maioria das amostras de efluentes, e entre eles, os PBTA 3 e 4 foram os que mais contribuíram para a atividade mutagênica verificada nesses extratos. Nesse estudo as técnicas de blue rayon em colunas e in situ foram comparadas, apresentando desempenho similar para recuperação desses compostos ${ }^{20}$.
Um método para determinação dos PBTA 1 e 2, baseado em extração em fase sólida, com Empore disk $\mathrm{C}_{18}$, e CLAE-espectrometria de massas (EM) "tandem" com ionização por "electrospray", foi proposto por Moriwaki et al. ${ }^{21}$. A porcentagem de recuperação desse método foi avaliada com a adição dos padrões de PBTA nas concentrações 5,0 e 10,0 ng/L de água de rio. Para o PBTA-1 foram observadas porcentagens de recuperação de 87 e $101 \%$, e para o PBTA-2, 106 e $104 \%$, respectivamente. Esse método se mostrou rápido, seletivo e sensível para a determinação de ambos PBTA em águas de rio, presentes na faixa de concentração de ng/L. Utilizando a técnica de extração descrita anteriormente ${ }^{21}$ e CLAE/EM/EM, Moriwaki et al. $.^{22} \mathrm{de}-$ senvolveram um método para a determinação simultânea dos oito PBTA conhecidos. Os limites de detecção para esses compostos em águas de rio variaram entre 0,04 e $0,5 \mathrm{ng} / \mathrm{L}$, e as porcentagens de recuperação variaram entre 65 e $127 \%$. Nas amostras de dois pontos, localizados nos rios Katsura e Nishitakase, os PBTA 2, 3, 4, 6 e 8 foram determinados em concentrações variando entre 0,10 e 17 ng/L. Embora os picos relativos ao PBTA-7 tenham sido observados, suas concentrações estavam abaixo do limite de quantificação e, portanto, não foram calculadas. Nesse trabalho, os PBTA 1 e 5 não foram detectados nas amostras avaliadas. Watanabe et al. ${ }^{23}$ sugerem que o PBTA-5 não foi encontrado nas amostras analisadas, porque o grupo bis(2acetoxietil)amino desse PBTA foi hidrolizado a bis(hidroxietil)amino durante os processos industriais de tingimento ou durante o tratamento dos efluentes industriais.

Recentemente, Ohe et al. ${ }^{9}$ avaliaram a mutagenicidade e os níveis de PBTA em efluentes, sedimentos, águas de rios (Yodo, Uji, Katsura, Nishitakase e Kizu) e águas tratadas para abastecimento público. Do total de extratos de blue rayon in situ obtidos dos rios avaliados entre os anos de 1996 e 2005, 50\% apresentaram mutagenicidade classificada como extrema (> 100.000 revertentes/g equivalente de blue rayon para a linhagem YG1024 do teste de Salmonella / microssoma). As maiores concentrações de PBTA-1 e 2 foram observadas nos efluentes finais das estações de tratamento, que recebem efluentes domésticos e industriais. As amostras de sedimento apresentaram atividade mutagênica com perfil semelhante ao das amostras de efluentes e de águas de rio, porém, apenas traços dos PBTA-2 e 3 foram detectados nessas amostras, indicando a presença de outros compostos genotóxicos. Os autores sugeriram que os PBTA, ao contrário de outros compostos policíclicos, não têm tendência de se acumularem nos sedimentos dos corpos d'água. Nas amostras de água tratada não foi detectada a presença de compostos dessa classe, nem de atividade mutagênica nas condições de teste.

Watanabe et al. ${ }^{24}$ determinaram quatro PBTA não-clorados em extratos mutagênicos do rio Ho em Shizuoka (Japão), utilizando blue rayon in situ e fracionamento em coluna cromatográfica Sephadex LH-20 (30 mm x $480 \mathrm{~mm}$ ) e CLAE. Os compostos identificados foram 2-[2-(acetilamino)-4-[N-(2-cianoetil)etilamino]-5metoxifenil]-6-amino-4-bromo-2H-benzotriazol (PBTA não-clorado2), 2-[2-(acetilamino)-4-[(2-hidroxietil)amino]-5-metoxifenil]-6amino-4-bromo-2 $H$-benzotriazol (PBTA não-clorado-3), 2-(2acetilamino-4-amino-5-metoxifenil)-6-amino-4-bromo- $2 \mathrm{H}$ benzotriazol (PBTA não-clorado-4) e 2-[2-(acetilamino)-4(dietilamino)-5-metoxifenil]-6-amino-4-bromo-2 $H$-benzotriazol (PBTA não-clorado-7). Anteriormente apenas o PBTA não-clorado1 havia sido identificado em amostras ambientais ${ }^{25}$.

Embora as características das estruturas químicas dos PBTA sugiram que sua origem esteja ligada aos corantes utilizados em processos de tingimento, sua formação no ambiente e sua presença nos corpos d'água ainda não estão totalmente esclarecidas. Com o objetivo de entender sua formação, e de produzir quantidades necessárias para a completa avaliação toxicológica desses novos contaminantes, procedimentos para síntese desses compostos foram propostos ${ }^{15-17,25}$. 


\section{SÍNTESE DOS PBTA}

Shiozawa et al. ${ }^{25}$ descreveram a síntese do PBTA-1 a partir de um corante azóico, através da sua redução por hidrossulfito de sódio e subseqüente cloração por hipoclorito de sódio (Figura 2). Considerando as possíveis rotas sintéticas do PBTA-1, os autores direcionaram seus esforços os vários substituintes presentes na molécula, como bromo, cloro, amino, metoxi, acetilamino e bis(2metoxietil)amino e no próprio esqueleto 2-fenilbenzotriazol, que é formado por ciclização do [(o-nitrofenil)hidrazo]benzeno ou [(oaminofenil)azo]benzeno.
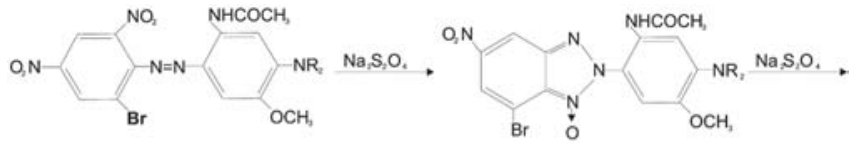

Disperse Bule 301 Nitro-não-CIPBTA-1-oxido<smiles>COc1cc(NC(=O)O)c(N2NC3C=C(N)C=C(Br)C3N2)cc1OC</smiles>

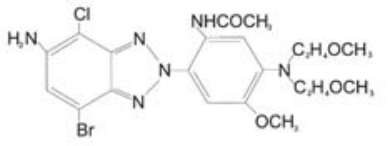

PBTA-1

Figura 2. Rota sintética do PBTA-1 proposta por Shiozawa et al. ${ }^{30}$

Seguindo a mesma rota sintética descrita por Shiozawa et al..$^{25}$ variando o azo corante precursor, outros seis PBTA foram sintetiza$\operatorname{dos}^{7,15-18}$. O objetivo das sínteses foi obter padrões para serem utilizados na determinação desses compostos em amostras ambientais, e obter quantidades suficientes de cada composto para a realização de testes para avaliação de sua toxicidade ${ }^{26}$. Os azo corantes precursores dos PBTA de 1 a 8 (Tabela 1) apresentam em comum a estrutura 2-[(2-bromo-4,6-dinitrofenil)azo]-4-metoxiacetilanelida como parte das suas moléculas, essencial para sua formação ${ }^{18}$.

Basicamente, a formação de todos os PBTA, exceto o PBTA-6, ocorre através da redução do corante azóico precursor (dinitrofenilazo corantes) por ação do hidrossulfito de sódio formando um composto intermediário chamado de PBTA não-clorado e em seguida esse intermediário é clorado pela adição de hipoclorito de sódio (Tabela 1). O PBTA-6 é um produto de hidrólise do PBTA-5 formado sob condições alcalinas ${ }^{26}$. Na Tabela 2 são apresentadas propriedades físico-químicas dos PBTA.
No Brasil, Oliveira et al..$^{27}$ verificaram a presença de compostos com atividade mutagênica similares aos PBTA em águas para abastecimento público. Nesse caso os compostos foram produzidos em laboratório a partir da adição de ditionito de sódio seguido de cloração com cloro-gás de um produto comercial que continha os corantes C.I. Disperse Blue 373, C.I. DisperseViolet 93 e C.I. Disperse Orange 37. A etapa de cloração foi realizada simulando o processo de desinfecção de água que ocorre na Estação de Tratamento de Água (ETA) localizada no Ribeirão dos Cristais, o qual sabidamente continha os corantes citados ${ }^{28}$. Os compostos gerados no laboratório foram utilizados como padrões para sua identificação nas amostras de água tratada produzida pela referida ETA. Os autores ainda estão identificando as estruturas dos compostos identificados bem como validando as técnicas para a sua quantificação. Os dados obtidos sugerem que os fenilbenzotriazóis detectados nas águas produzidas pela ETA estejam sendo formados no ambiente em duas etapas distintas. A formação dos fenilbenzotriazóis não clorados parece ocorrer na indústria de tingimento, que utiliza agentes redutores para a descoloração dos corantes não ligados às fibras têxteis. Estes, uma vez lançados no ribeirão como constituintes dos efluentes industriais, ao atingirem a ETA reagem com o cloro na etapa conhecida como pré-cloração, gerando os compostos similares aos PBTA já descritos na literatu$\mathrm{ra}^{27}$. Os mesmos autores também estudaram a mutagenicidade dos efluentes industriais, que eram liberados no Ribeirão dos Cristais, e diversos corantes e aminas aromáticas mutagênicas foram identificadas e a contribuição dos corantes na mutagenicidade dos efluentes foi avaliada com sucesso ${ }^{29}$.

\section{TOXICIDADE DOS PBTA}

Os PBTA, PBTA não clorados e os seus corantes azóicos precursores apresentam atividade mutagênica para diferentes linhagens de Salmonella typhimurium do teste de Salmonella/ microssoma $^{24}$ (Tabela 3). Particularmente, os PBTA apresentam maior atividade mutagênica para a linhagem YG1024 na presença de sistema de ativação metabólica (mistura S9) ${ }^{26}$ quando comparados com seus precursores.

Shiozawa et al. $^{30}$ avaliaram a mutagenicidade do PBTA-1 com o objetivo de elucidar a relação estrutura-atividade desse composto. Os dados sugeriram que o grupamento amino primário é essencial para a atividade mutagênica desse composto, como observado para outras aminas; por exemplo, 2-amino-3,8-dimetilimidazol[4,5-

Tabela 2. Propriedades físico-químicas dos PBTA

\begin{tabular}{|c|c|c|c|c|c|c|}
\hline PBTA & Número CAS & Peso molecular & Ponto de fusão $\left({ }^{\circ} \mathrm{C}\right)$ & Solubilidade $(\mathrm{g} / \mathrm{L})^{\mathrm{a}}$ & $\mathrm{pKa}$ & Volume molar $\left(\mathrm{cm}^{3} / \mathrm{mol}\right)^{\mathrm{d}}$ \\
\hline PBTA-1 & $194590-84-6$ & 542 & $165-166$ & $3,3 \times 10^{-3}$ & $\begin{array}{r}13,38( \pm 0,70)^{\mathrm{b}} \\
3,34( \pm 0,50)^{\mathrm{c}}\end{array}$ & $352,4( \pm 7,0)$ \\
\hline PBTA-2 & $215245-16-2$ & 507 & $179-181$ & $6,6 \times 10^{-4}$ & $\begin{array}{r}13,25( \pm 0,70)^{\mathrm{b}} \\
3,42( \pm 0,50)^{\mathrm{c}}\end{array}$ & $321,0( \pm 7,0)$ \\
\hline PBTA-3 & $270925-57-0$ & 470 & $231-234$ & $9,9 \times 10^{-3}$ & $\begin{aligned} 13,32 & ( \pm 0,70)^{\mathrm{b}} \\
2,04 & ( \pm 0,50)^{\mathrm{c}}\end{aligned}$ & $268,2( \pm 7,0)$ \\
\hline PBTA-4 & $351995-07-8$ & 426 & $>230$ & $97,7 \times 10^{-3}$ & $\begin{array}{r}13,31( \pm 0,70)^{\mathrm{b}} \\
2,43( \pm 0,10)^{\mathrm{c}}\end{array}$ & $230,9( \pm 7,0)$ \\
\hline PBTA-5 & - & 598 & - & - & - & - \\
\hline PBTA-6 & $392274-07-6$ & 514 & - & 0,013 & $\begin{array}{r}13,39( \pm 0,70)^{\mathrm{b}} \\
3,64( \pm 0,50)^{\mathrm{c}}\end{array}$ & $303,6( \pm 7,0)$ \\
\hline PBTA-7 & - & 482 & $200-202$ & 480 & - & - \\
\hline PBTA-8 & - & 506 & $173-175$ & 504 & - & - \\
\hline
\end{tabular}

-: Dados não encontrados na literatura; a: Solubilidade em água a $25^{\circ} \mathrm{C}$ em pH 7; b: pKa determinado em meio ácido a $25^{\circ} \mathrm{C}$; c: pKa determinado em meio básico a $25{ }^{\circ} \mathrm{C}$; d: Volume molar determinado a $20{ }^{\circ} \mathrm{C}$ e pressão de 760 Torr 
Tabela 3. Atividade mutagênica expressa em número de revertentes por $\mu \mathrm{g}$ dos diversos PBTA frente as diferentes linhagens de Salmonella typhimurium na presença de ativação metabólica (mistura S9)

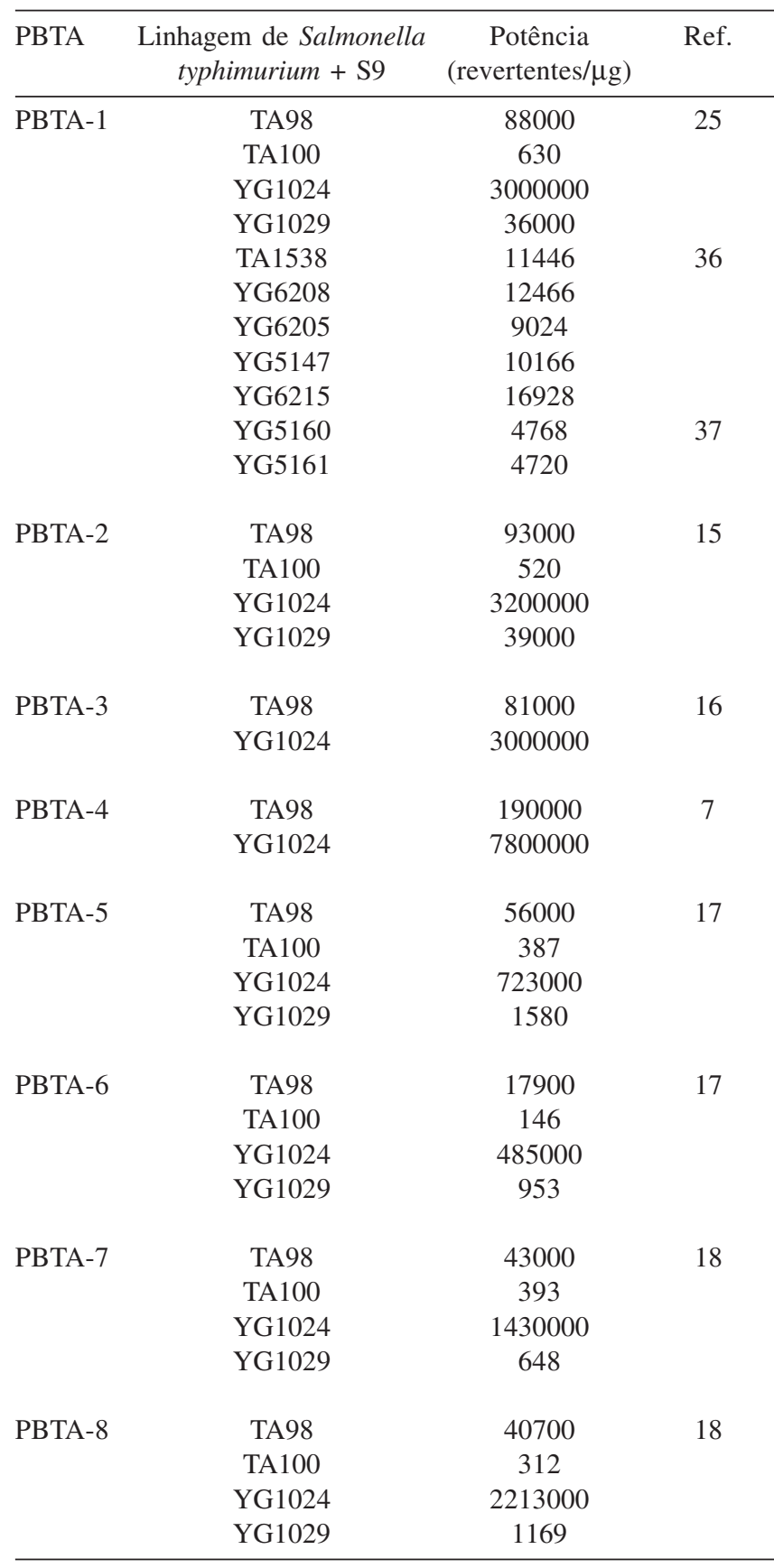

f]quinoxalina (MeIQx), 3-amino-1,4-dimetil-5H-pirido[4,3-b]indol (Trp-P-1), 3-amino-1-metil-5H-pirido[4,3-b]indol (Trp-P-2), 2amino-1-metil-6-fenilmidazol[4,5- $b$ ] piridina (PhPI) entre outras ${ }^{31,32}$. Outras características moleculares do PBTA-1 relacionadas a sua atividade mutagênica são a planaridade e a presença de halogênios ${ }^{30}$. Ohe et al. ${ }^{33}$ determinaram o espectro de mutação dos PBTA 1 e 2 utilizando as linhagens Salmonella typhimurium TA98, TA100 e TA104 e verificaram que os espectros obtidos foram similares entre si quando comparados aos espectros produzidos por outras aminas aromáticas genotóxicas.

O PBTA-2, na presença e na ausência de mistura S9, foi avaliado quanto a sua capacidade de induzir a formação de micronúcleos in vitro, em células de roedores (CHL e V79-MZ). Esse composto apresentou resultados fracamente positivos para a linhagem CHL e fortemente positivos para a linhagem V79-MZ. Nesse trabalho também foi observado que o PBTA-2 foi capaz de induzir poliploidia em ambas culturas de células avaliadas ${ }^{34}$. Um ano mais tarde (2001) Matsuoka et al. ${ }^{8}$ analisaram os PBTA 1 e 2, seus corantes azóicos precursores e os PBTA não-clorados utilizando as mesmas linhagens de células do estudo anterior, e verificaram que o PBTA-2 é mais citotóxico que o PBTA-1. O PBTA-2 e seu corante precursor induziram células binucleadas e núcleos multilobulados, respectivamente. Os autores sugeriram que outros PBTA não-clorados e os próprios PBTA teriam efeitos similares devido ao esqueleto fenilbenzotriazol comum a essa classe de compostos.

A genotoxicidade do PBTA-6 foi avaliada através dos testes de micronúcleos e do cometa em peixes (Carassius auratus) ${ }^{35}$. Esse composto foi capaz de induzir micronúcleos em células de brânquias, principalmente nas doses de 50 e $100 \mathrm{mg} / \mathrm{kg}$, porém não foi observado aumento na freqüência de micronúcleos nos eritrócitos de sangue periférico. Para o ensaio cometa o PBTA-6 também apresentou respostas positivas. Os autores sugeriram, com base nas suas propriedades mutagênicas, que o potencial carcinogênico dos mesmos seja avaliado tanto em organismos aquáticos como em roedores ${ }^{35}$.

\section{CONSIDERAÇÕES FINAIS}

Análises químicas direcionadas pelo efeito biológico (ADEB) realizadas em amostras ambientais podem auxiliar na identificação de novos compostos com a vantagem de priorizar aqueles que causam efeitos adversos aos organismos, a exemplo dos PBTA. Embora os PBTA apresentem efeitos genotóxicos comprovados para bactérias, peixes e culturas celulares de mamíferos a avaliação de sua toxicidade, bem como dos PBTA não-clorados, deverá ser aprofundada para se determinarem os riscos da presença dos mesmos no ambiente.

No Brasil, os PBTA e os PBTA não-clorados ainda não foram identificados em corpos de água, porém compostos de estrutura química similar aos PBTA foram detectados em águas de abastecimento público ${ }^{27}$. Enquanto não se conhecem os valores seguros de exposição ambiental para os PBTA e seus precursores, métodos analíticos para sua identificação e quantificação devem ser desenvolvidos no Brasil, visando o monitoramento dos mesmos em águas que recebem efluentes de indústrias de tingimento. Medidas que visem a minimização de sua formação e/ou lançamento deveriam ser consideradas especialmente em mananciais utilizados para abastecimento público, considerando que o tratamento efetuado pelas indústrias pode não ser eficiente para sua remoção.

\section{REFERÊNCIAS}

1. Hewitt, L. M.; Marvin, C. H.; Mutat. Res./Rev. Mutat. Res. 2005, 589, 208.

2. Brack, W.; Anal. Bioanal. Chem. 2003, 377, 397.

3. Enya, T.; Suzuki, H.; Watanabe, T.; Hirayama, T.; Hisamatsu, Y.; Environ. Sci. Technol. 1997, 31, 2772

4. Meier, J. R.; Mutat. Res./Rev. Genet. Toxicol. 1988, 196, 211.

5. Nukaya, H.; Yamashita, J.; Tsuji, K.; Terao, Y.; Ohe, T.; Sawanishi, H.; Katsuhara, T.; Kiyokawa, K.; Tezuca, M.; Oguri, A.; Sugimura, T.; Wakabayashi, K.; Chem. Res. Toxicol. 1997, 10, 1061.

6. Ohe, T.; Takeuchi, N.; Watanabe, T.; Tada, A.; Nukaya, H.; Terao, Y.; Sawanishi, H.; Hirayama, T.; Sugimura, T.; Wakabayashi, K.: Environ. Health Perspect. 1999, 107, 701.

7. Nukaya, H.; Shiozawa, T.; Tada, A.; Terao, Y.; Ohe, T.; Watanabe, T.; Asanoma, M.; Sawanishi, H.; Katsuhara, T.; Sugimura, T.; Wakabayashi, K.; Mutat. Res./Genet. Toxicol. Environ. Mutagen. 2001, 492, 73.

8. Matsuoka, A.; Tada, A.; Terao, Y.; Nukaya, H.; Önfelt, A.; Wakabayashi, K.; Mutat. Res./Genet. Toxicol. Environ. Mutagen. 2001, 493, 75.

9. Ohe, T.; Mizuno, T.; Morisawa, T.; Kiritani, S.; Suzuki, S.; Takehana, H.; Kasetani, S.; Watanabe, T.; Nukaya, H.; Shiozawa, T.; Terao, Y.; Wakabayashi, K.; Genes Environ. 2006, 28, 108. 
10. Kummrow, F.; Magalhães, D.; Franco, A.; Umbuzeiro, G. A.; Rev. Saúde Pública 2006, 40, 890.

11. Umbuzeiro, G. A.: Roubicek, D. A.; Rech, C. A.; Sato, M. I. Z.; Claxton, L. D.; Chemosphere 2004, 54, 1589.

12. Roubicek, D. A.; Umbuzeiro, G. A. Em Métodos de coleta, análises físicoquímicas e ensaios biológicos e ecotoxicológicos de sedimentos de água doce; Mozeto, A. A.; Umbuzeiro, G. A.; Jardim, W. F., eds.; Cubo Multimidia: São Carlos, 2006, cap. 4.

13. Nukaya, H.; Tsuji, K.; Ohe, T.; Oguri A.; Sugimura T.; Wakabayashi, K.; Mutat. Res./Fundam. Mol. Mech. Mutagen. 1997, 379, 102.

14. Sakamoto, H.; Hayatsu, H.; Bull. Environ. Contam. Toxicol. 1990, 44, 521.

15. Oguri, A.; Shiozawa, T.; Terao, Y.; Nukaya, H.; Yamashita, J.; Ohe, T.; Sawanishi, H.; Katsuhara, T.; Sugimura, T.; Wakabayashi, K.; Chem. Res. Toxicol. 1998, 11, 1195.

16. Shiozawa, T.; Tada, A.; Nukaya, H.; Watanabe, T.; Takahashi, T.; Asanoma, M.; Ohe, T.; Sawanishi, H.; Katsuhara, T.; Sugimura, T.; Wakabayashi, K.; Terao, Y.; Chem. Res. Toxicol. 2000, 13, 535.

17. Watanabe, T.; Nukaya, H.; Terao, Y.; Takahashi; Y.; Tada, A.; Takamura, T; Sawanishi, H.; Ohe, T.; Hirayama, T.; Sugimura, T.; Wakabayashi, K.; Mutat. Res./Genet. Toxicol. Environ. Mutagen. 2001, 498, 107.

18. Watanabe, T.; Shiozawa, T.; Takahashi, Y.; Takahashi, T.; Terao, Y.; Nukaya, H.; Takamura, T.; Sawanishi, H.; Ohe, T.; Hirayama, T.; Wakabayashi, K.; Mutagenesis 2002, 17, 293.

19. Watanabe, T.; Takahashi, Y.; Takahashi, T.; Nukaya, H.; Terao, Y.; Hirayama, T.; Wakabayashi, K.; Mutat. Res./Genet. Toxicol. Environ. Mutagen. 2002, 519, 187.

20. Morisawa, T.; Mizuno, T.; Ohe, T.; Watanabe, T.; Hirayama, T.; Nukaya, H.; Shiozawa, T.; Terao, Y.; Sawanishi, H.; Wakabayashi, K.; Mutat. Res./ Genet. Toxicol. Environ. Mutagen. 2003, 534, 123.

21. Moriwaki, H.; Harino, H.; Hashimoto, H.; Arakawa, R.; Ohe, T.; Yoshikura, T.; J. Chromatogr., A 2003, 995, 239.

22. Moriwaki, H.; Harino, H.; Yoshikura, T.; Ohe, T.; Nukaya, H.; Terao, Y.; Sawanishi, H.; Wakabayashi, K.; Miyakoda, H.; Alary, J. F.; J. Environ. Monit. 2004, 6, 897.
23. Watanabe, T.; Ohe, T.; Hirayama, T.; Environ. Sci. 2005, 12, 325.

24. Watanabe, T.; Ohba, H.; Asanoma, M.; Hasei, T.; Takamura, T.; Terão, Y.; Shiozawa, T.; Hirayama, T.; Wakabayashi, K.; Nukaya, H.; Mutat. Res./ Genet. Toxicol. Environ. Mutagen. 2006, 609, 137.

25. Shiozawa, T.; Muraoka, K.; Nukaya, H.; Ohe, T.; Sawanishi, H.; Oguri, A.; Wakabayashi, K.; Sugimura, T.; Terao, Y.; Chem. Res. Toxicol. 1998, 11,375 .

26. Ohe, T.; Watanabe, T.; Wakabayashi, K.; Mutat. Res./Rev. Mutat. Res. 2004, $567,109$.

27. Oliveira, D. P.; Carneiro, P. A.; Rech, C. M.; Zanoni, M. V. B.; Claxton, L. D.: Umbuzeiro, G. A.: Environ. Sci. Technol. 2006, 40, 6682.

28. Umbuzeiro, G. A.: Freeman, H. S.; Warren, S. H.; Oliveira, D. P.; Terão, Y.; Watanabe, T.; Claxton, L. D.; Chemosphere 2005, 60, 55.

29. Oliveira, D. P.; Carneiro, P. A.; Sakagami, M. K.; Zanoni, M. V. B.; Umbuzeiro, G. A.; Mutat. Res./Genet. Toxicol. Environ. Mutagen. 2007, 626, 137.

30. Shiozawa, T.; Suyama, K.; Nakano, K.; Nukaya, H.; Sawanishi, H.; Oguri, A.; Wakabayashi, K.; Terao, Y.; Mutat. Res./Genet. Toxicol. Environ. Mutagen. 1999, 442, 105.

31. Ohe, T.; Mutat. Res./Genet. Toxicol. Environ. Mutagen. 1997, 393, 73.

32. Skog, K.; J. Chromatogr., B: Anal. Technol. Biomed. Life Sci. 2004, 802, 39.

33. Ohe, T.; Shaughnessy, D. T.; Landi, S.; Terao, Y.; Sawanishi, H.; Nukaya, H.; Wakabayashi, K.; DeMarini, D. M.; Mutat. Res./Fundam. Mol. Mech. Mutagen. 1999, 429, 189.

34. Matsuoka, A.; Sakamoto, H.; Tadokoro, S.; Tada, A.; Terao, Y.; Nukaya, H.; Wakabayashi, K.; Mutat. Res./Genet. Toxicol. Environ. Mutagen. 2000, $464,161$.

35. Masuda, S.; Deguchi, Y.; Masuda, Y.; Watanabe, T.; Nukaya, H.; Terão, Y.; Takamura, T.; Wakabayashi, K.; Kinae, N.; Mutat. Res./Genet. Toxicol. Environ. Mutagen. 2004, 560, 33.

36. Kokubo, K.; Yamada, M.; Kanke, Y.; Nohmi, T.; DNA Repair 2005, 4, 1160.

37. Matsui, K.; Yamada, M.; Imai, M.; Yamamoto, K.; Nohmi, T.; DNA Repair 2006, 5, 465 . 